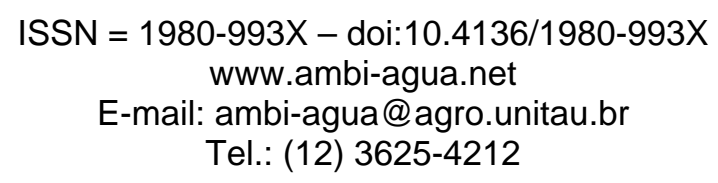

\title{
Estimativa da erosividade local das chuvas, utilizando redes neurais artificiais
}

\author{
(http://dx.doi.org/10.4136/ambi-agua.197)
}

\author{
Teodorico Alves Sobrinho ${ }^{1}$; Caroline Alvarenga Pertussatti ${ }^{2}$; Lais Cristina Soares \\ Rebucci $^{1}$; Paulo Tarso Sanches de Oliveira ${ }^{3}$ \\ ${ }^{1}$ Universidade Federal de Mato Grosso do Sul, UFMS, e-mail: talves@pq.cnpq.br; laisrebucci@hotmail.com \\ ${ }^{2}$ Universidade de Brasília, UnB; e-mail: caper88@gmail.com \\ ${ }^{3}$ Universidade de São Paulo, USP; e-mail: paulot@sc.usp.br
}

\section{RESUMO}

A obtenção de valores locais de erosividade da chuva é fundamental para a estimativa da perda de solo a partir do modelo Universal Soil Loss Equation (USLE), sendo assim, útil no planejamento conservacionista do solo e da água. Desse modo, objetivou-se no presente estudo, desenvolver uma Rede Neural Artificial (RNA) capaz de estimar, com precisão satisfatória, a erosividade da chuva em qualquer localidade do Estado de Mato Grosso do Sul. Para tanto, foram utilizados dados de erosividade da chuva, latitude, longitude e altitude de estações pluviométricas e pluviográficas localizadas no Estado para o treinamento e teste de uma RNA. Após o treinamento com várias configurações de rede, selecionou-se a que apresentou melhor desempenho, ou seja, maior coeficiente de determinação, calculado com base nos dados de erosividade da amostra teste e dos respectivos valores estimados pela RNA. $\mathrm{Na}$ avaliação dos resultados obtidos, foram utilizados, além do coeficiente de determinação, o índice de confiança e o índice de concordância. Verificou-se que é possível estimar a erosividade da chuva para qualquer localidade do Estado de Mato Grosso do Sul, de forma confiável, utilizando-se apenas dados de coordenadas geográficas e altitude.

Palavras-chave: inteligência artificial; conservação do solo; erosão hídrica.

\section{Estimation of local rainfall erosivity using artificial neural network}

\section{ABSTRACT}

The information retrieval of local values of rainfall erosivity is essential for soil loss estimation with the Universal Soil Loss Equation (USLE), and thus is very useful in soil and water conservation planning. In this manner, the objective of this study was to develop an Artificial Neural Network (ANN) with the capacity of estimating, with satisfactory accuracy, the rainfall erosivity in any location of the Mato Grosso do Sul state. We used data from rain erosivity, latitude, longitude, altitude of pluviometric and pluviographic stations located in the state to train and test an ANN. After training with various network configurations, we selected the best performance and higher coefficient of determination calculated on the basis of data erosivity of the sample test and the values estimated by ANN. In evaluating the results, the confidence and the agreement indices were used in addition to the coefficient of determination. It was found that it is possible to estimate the rainfall erosivity for any location in the state of Mato Grosso do Sul, in a reliable way, using only data of geographical coordinates and altitude.

Keywords: artificial intelligence; soil conservation; water erosion. 


\section{INTRODUÇÃO}

A erosão hídrica é caracterizada como uma das significativas formas de degradação ambiental, sendo influenciada por diversos fatores, tais como: atributos físicos, químicos e biológicos do solo; topografia; uso e ocupação do solo e clima (Oliveira et al., 2009). Assim, foram desenvolvidos modelos matemáticos para predizer a erosão do solo com intuito de proporcionar a avaliação dos impactos na agricultura, solos e recursos hídricos e fornecer informações úteis na tomada de decisão no planejamento conservacionista do solo e água (Renschler e Harbor, 2002; Schiettecatte et al., 2008; Oliveira et al., 2010). Dentre os modelos empíricos de predição da erosão, pode-se destacar a Universal Soil Loss Equation (USLE) proposta por Wischmeier e Smith (1978).

A USLE é composta por seis fatores que resultam na estimativa da perda de solo média anual, sendo: erosividade (R); erodibilidade (K); comprimento de rampa (L); declividade (S); uso e manejo do solo $(\mathrm{C})$ e práticas conservacionistas $(\mathrm{P})$. Todos esses fatores devem ser estudados de forma individual e local antes da aplicação do modelo (Onyando et al., 2005; Irvem et al., 2007). A erosividade da chuva (fator R) é considerada como um dos fatores mais importantes na estimativa de perda de solos (Shamshad et al., 2008). Segundo Mannaerts e Gabriels (2000), o conhecimento do comportamento da erosividade e da distribuição sazonal dessa variável auxiliam no planejamento conservacionista do solo e da água, proporcionando a realização de projetos para melhorar o controle da erosão hídrica.

A determinação da erosividade da chuva envolve um trabalho exaustivo de seleção e leitura de uma série de registros pluviográficos, sendo esses dados escassos e, muitas vezes, de difícil acesso (Mello et al., 2007; Capolongo et al., 2008). Assim, para viabilizar a obtenção do Fator R foram propostos modelos que relacionam o índice de erosividade com dados de precipitação (e.g. mensal, totais anuais pluviométricos e o índice de Fournier modificado) (Renard e Freimund, 1994). Esses registros pluviométricos diários geralmente estão disponíveis para a maioria das localidades com boa cobertura espacial e temporal, permitindo a obtenção do índice de erosividade, com boa precisão, em regiões com ausência de dados pluviográficos (Silva, 2004; Angulo-Martínez e Beguería, 2009).

A partir de estimativas de valores pontuais, informações sobre erosividade podem ser obtidas em locais com ausência ou com informações restritas de precipitação, por meio de métodos de interpolação ou a partir de técnicas de aprendizagem de máquina (Machine Learning - ML). Uma das principais técnicas de ML são as Redes Neurais Artificiais (RNAs). Nesse sentido, alguns autores têm utilizado as RNAs para realizar a estimativa dos valores de erosividade, considerando o uso dessa técnica viável e eficiente (Licznar, 2005; Moreira et al., 2006, 2008 e 2009; Silva et al., 2010).

Dessa forma, objetivou-se desenvolver uma rede neural artificial capaz de estimar, com precisão satisfatória, a erosividade da chuva em qualquer localidade do Estado de Mato Grosso do Sul.

\section{MATERIAL E MÉTODOS}

O estudo foi realizado para o Estado de Mato Grosso do Sul, que apresenta área total de $358.158,7 \mathrm{~km} 2$. Os dados de entrada utilizados na RNA foram obtidos do trabalho desenvolvido por Oliveira (2011), e correspondem à erosividade da chuva, latitude, longitude e altitude, referentes a 109 estações pluviométricas e 3 estações pluviográficas (Figura 1). 


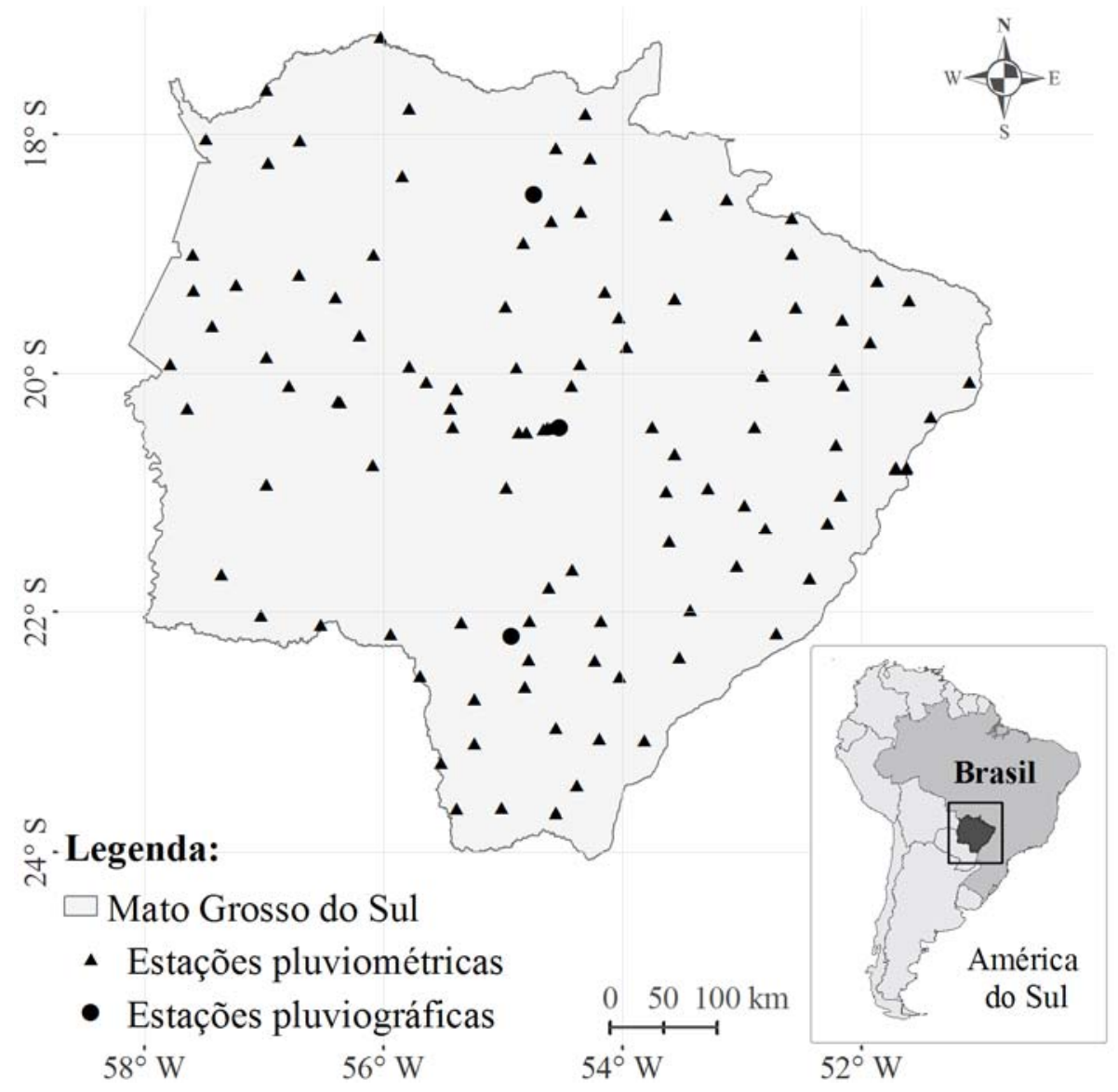

Figura 1. Estações pluviográficas e pluviométricas localizadas em Mato Grosso do Sul.

Fonte: Oliveira (2011).

Para o treinamento e teste das RNAs, utilizou-se o software Matlab (Mathworks, 2008), sendo escolhidas aleatoriamente 90 estações para o treinamento das RNAs, enquanto as 22 restantes foram utilizadas para teste das redes.

As arquiteturas das RNAs foram do tipo $3-n 1-n 2-1$, sendo: um vetor de entrada com três variáveis, duas camadas intermediárias com $\mathrm{n} 1$ e $\mathrm{n} 2$ neurônios artificiais e um neurônio na camada de saída. O vetor de entrada foi composto pelos valores de latitude e longitude de cada estação, em graus decimais, bem como pelo valor de sua altitude, em metros. No neurônio da camada de saída empregou-se uma função de ativação linear para fornecer o valor da erosividade da chuva da localidade representada, em $\mathrm{MJ} \mathrm{mm} \mathrm{h}^{-1} \mathrm{ha}^{-1} \mathrm{ano}^{-1}$.

Para garantir que cada parâmetro de entrada recebesse igual atenção durante 0 treinamento, aumentando assim sua eficiência, tanto os dados de entrada quanto os dados de saída foram normalizados para o intervalo entre 0 e 1, por meio de lógica fuzzy, utilizando-se função sigmoidal crescente (Equação 1).

$$
\mu(x)=\cos 2 \alpha \text { e } \alpha=(1-(x-a) /(b-a)) \cdot \pi / 2 \text { se } x \geq a \text { e } x \leq b
$$

em que: a, b, c, d são parâmetros ou valores modais da função e $\mu(x)$ é o grau de pertinência.

As RNAs foram treinadas utilizando o algoritmo de aprendizado de Retropropagação do Erro, em que os parâmetros w's (pesos) e b's (bias) são atualizados por uma regra de treinamento, tendo sido adotada a de Levenberg-Marquardt (Marquardt, 1963). 
AlveS SOBRINHO, T.; PERTUSSATTI, C. A.; REBUCCI, L. C. S.; OLIVEIRA, P. T. S. Estimativa da erosividade local das chuvas, utilizando redes neurais artificiais. Ambi-Agua, Taubaté, v. 6, n. 2, p.246-254, 2011. (doi:10.4136/ambi-agua.197)

Visando ao mapeamento desejado, foram treinadas diversas topologias de redes, variando-se o número de neurônios, funções de ativação nas camadas intermediárias, bem como o número de iterações (Tabela 1).

Tabela 1. Parâmetros testados no treinamento das RNAs.

\begin{tabular}{l|l}
\hline \multicolumn{1}{c|}{ Parâmetro } & \multicolumn{1}{c}{ Valores } \\
\hline Número de neurônios nas camadas intermediárias & 1 a $5 ; 1$ a 5 \\
Funções de ativação nas camadas intermediárias & Logística Sigmóide; Tangente Hiperbólica Sigmóide \\
Número de ciclos & $50 ; 100 ; 200 ; 500$ \\
\hline
\end{tabular}

Tendo em vista que, no início do treinamento, os parâmetros livres são gerados aleatoriamente e que esses valores iniciais podem influenciar no resultado final do treinamento, cada arquitetura de rede foi treinada dez vezes, sendo selecionada a que apresentou maior valor de coeficiente de determinação $\left(r^{2}\right)$. Esse coeficiente foi calculado a partir dos dados de erosividade das 22 estações da amostra de teste e os respectivos valores estimados pela RNA.

Os valores de erosividade estimados pela RNA foram comparados com os calculados por Oliveira (2011), utilizando-se o erro percentual acumulado, o Erro Relativo Médio (ERM), o coeficiente de exatidão de Willmott (d) e o índice de desempenho (c).

O ERM foi calculado a partir da Equação 2.

$$
\mathrm{ERM}=\sum_{i=1}^{n} \frac{|(R o-R i)|}{\mathrm{Ro}} \times \frac{1}{n}
$$

em que: $\mathrm{n}$ = número de observações; Ro = valor calculado da erosividade da chuva da estação i, MJ mm ha ${ }^{-1} \mathrm{~h}^{-1}$ ano $^{-1}$; e Ri = valor estimado da erosividade da chuva para a estação i, MJ $\mathrm{mm} \mathrm{ha}^{-1} \mathrm{~h}^{-1} \mathrm{ano}^{-1}$.

Segundo Camargo e Sentelhas (1997), os seguintes indicadores estatísticos são considerados para correlacionar os valores estimados com os medidos: exatidão - índice de Willmott "d"; e de confiança ou desempenho "c". A exatidão, relacionada ao afastamento dos valores estimados em relação aos observados, é dada estatisticamente pelo índice de concordância "d" proposto por Willmott et al. (1985). Seus valores variam de zero, para nenhuma concordância, a 1, para a concordância perfeita. $O$ índice é dado pela Equação 3.

$$
\mathrm{d}=1-\left[\sum(\mathrm{Pi}-\mathrm{Oi})^{2} / \sum(|\mathrm{Pi}-\mathrm{O}|+|\mathrm{Oi}-\mathrm{O}|)^{2}\right]
$$

em que: $\mathrm{Pi}=$ valor estimado; $\mathrm{Oi}=$ valor observado; e, $\mathrm{O}=$ média dos valores observados.

O índice de desempenho (c) apresentado por Camargo e Sentelhas (1997) permite analisar conjuntamente a precisão e a exatidão dos resultados obtidos. Esse índice reúne os índices de precisão, dado pelo coeficiente de correlação (r) que indica o grau de dispersão dos dados obtidos em relação à média, ou seja, o erro aleatório e o de concordância $(\mathrm{d})$. $\mathrm{O}$ índice $\mathrm{c}$ é calculado conforme Equação 4.

$$
\mathrm{c}=\mathrm{r} \cdot \mathrm{d}
$$

Na Tabela 2, são apresentados os critérios de avaliação do desempenho da RNA quanto ao seu índice de confiança. 
AlveS SOBRINHO, T.; PERTUSSATTI, C. A.; REBUCCI, L. C. S.; OLIVEIRA, P. T. S. Estimativa da erosividade local das chuvas, utilizando redes neurais artificiais. Ambi-Agua, Taubaté, v. 6, n. 2, p.246-254, 2011. (doi:10.4136/ambi-agua.197)

Tabela 2. Análise do desempenho do modelo com base no índice de confiança "c".

\begin{tabular}{c|c}
\hline Valor de “c” & Desempenho \\
\hline$>0,85$ & Ótimo \\
0,76 a 0,85 & Muito Bom \\
0,66 a 0,75 & Bom \\
0,61 a 0,65 & Mediano \\
0,51 a 0,60 & Sofrível \\
0,41 a 0,50 & Mau \\
$\leq 0,40$ & Péssimo \\
\hline
\end{tabular}

\section{RESULTADOS E DISCUSSÃO}

A RNA selecionada apresentou melhor desempenho com a mínima configuração possível. Essa configuração é composta de uma camada de entrada com três variáveis, duas camadas intermediárias cada uma com 4 e 2 neurônios artificiais, respectivamente, e um neurônio na camada de saída. Para os neurônios da camada intermediária foi adotada a função de ativação do tipo Tangente Hiperbólica Sigmóide. Essa configuração de rede também foi avaliada como a mais satisfatória por Moreira et al. (2009), na estimativa mensal da erosividade da chuva no Estado de Minas Gerais por RNAs. Em geral, as redes treinadas apresentaram melhores desempenhos com números menores de ciclos, sendo que a RNA selecionada atingiu maior eficiência em 200 ciclos. Alem disso, verifica-se que redes com mais de 200 ciclos apresentam problemas de "memorização" (Moreira et al., 2009).

Os valores de erosividade da chuva calculados por Oliveira (2011) e os estimados pela RNA para as 22 estações da amostra de teste estão apresentados na Tabela 3.

Tabela 3. Valores de erosividade da chuva calculados e estimados pela RNA.

\begin{tabular}{|c|c|c|c|}
\hline Estação & RO (MJ mm h ha $^{-1}$ ano $^{-1}$ ) & RNA (MJ mm ho $\mathrm{ha}^{-1}$ ano $^{-1}$ ) & ER (\%) \\
\hline 1 & 8919,2 & 8786,7 & -1 \\
\hline 2 & 8764,7 & 8786,7 & 0 \\
\hline 3 & 8142,9 & 8076,1 & -1 \\
\hline 4 & 9251,9 & 9085,3 & -2 \\
\hline 5 & 8622,9 & 8724,2 & 1 \\
\hline 6 & 9032,0 & 8976,2 & -1 \\
\hline 7 & 7767,0 & 7679,2 & -1 \\
\hline 8 & 8456,0 & 8547,7 & 1 \\
\hline 9 & 9495,5 & 9434,2 & -1 \\
\hline 10 & 8745,5 & 8657,6 & -1 \\
\hline 11 & 9486,8 & 9384,0 & -1 \\
\hline 12 & 9137,1 & 9099,6 & 0 \\
\hline 13 & 9147,9 & 8999,7 & -2 \\
\hline 14 & 7916,4 & 7886,2 & 0 \\
\hline 15 & 8527,5 & 8657,6 & 2 \\
\hline 16 & 8957,6 & 8924,0 & 0 \\
\hline 17 & 8591,5 & 8547,7 & -1 \\
\hline 18 & 8006,0 & 8059,5 & 1 \\
\hline 19 & 9961,5 & 9634,1 & -3 \\
\hline 20 & 8935,5 & 9158,8 & 2 \\
\hline 21 & 8910,2 & 8562,8 & -4 \\
\hline 22 & 8660,9 & 8547,7 & -1 \\
\hline Mínimo & 7767,0 & 7679,2 & - \\
\hline Máximo & 9961,5 & 9634,1 & - \\
\hline Média & 8792,6 & 8737,1 & - \\
\hline Desvio Padrão & 537,5 & 497,4 & - \\
\hline Coeficiente de Variação & 0,1 & 0,1 & - \\
\hline
\end{tabular}

RO: valor calculado da erosividade da chuva da estação; RNA: valor estimado da erosividade da chuva da estação; ER: erro relativo percentual entre os valores de erosividade RO e RNA. 
Nota-se, pela Tabela 3, a semelhança entre os resultados estimados pela RNA com os valores calculados. Além disso, os erros relativos percentuais (ER) calculados são considerados baixos para a estimativa da erosividade da chuva. Quanto menor a porcentagem do erro, maior a eficiência do modelo (Silva et al., 2010). Esse comportamento caracteriza, portanto, que o uso de RNA acarreta pequenos ER na estimativa do valor de erosividade.

Constatou-se que a RNA subestimou os valores de erosividade da chuva em $0,63 \%$. Silva et al. (2010) também relatou subestimação dos valores de erosividade utilizando RNA. Já Moreira et al. (2006) verificaram que a RNA apresentou tendência de superestimar a erosividade da chuva. Assim, fica claro que o uso das RNAs não produz tendência única de subestimação ou superestimação dos valores de erosividade, sendo essa questão altamente dependente das condições locais de cada região, da qualidade e da quantidade dos dados de entrada e da escolha e configuração de rede a ser utilizada.

A correlação obtida entre a variável altitude e os valores de erosividade estimados pela RNA é classificada como baixa $(r=0,24)$. Isso pode ser explicado pela baixa variabilidade dos valores de altitude em todo o Estado. Silva et al. (2010) constataram que a altitude é a variável menos significativa para a determinação da erosividade da chuva utilizando RNAs, fato que pode ser explicado pela alta variação de altitude, o que comprova o baixo peso associado à esta no modelo. No entanto, Moreira et al. (2006), comparando os resultados de erosividade obtidos por RNAs com os calculados pelo método do inverso da distância, justificam o melhor desempenho das RNAs pela inserção de valores de altitude. Assim, tanto no presente trabalho como nos de Moreira et al. (2006) e Silva et al. (2010), o desempenho das RNAs é confiável e adequado para estimativa dos valores de erosividade; no entanto, é fundamental destacar que os resultados variam localmente, de acordo com os dados de entrada e a formatação da rede.

O valor médio anual da erosividade das chuvas para as 22 estações da amostra teste utilizadas foi de $8737 \mathrm{MJ} \mathrm{mm} \mathrm{h}^{-1} \mathrm{ha}^{-1}$ ano $^{-1}$, variando de 7679 a $9634 \mathrm{MJ} \mathrm{mm} \mathrm{h}^{-1} \mathrm{ha}^{-1}$ ano $^{-1}$. Verificou-se que a RNA apresentou baixo valor de ERM, igual a 0,006, podendo-se afirmar que esse método permite adequada estimativa dos valores da erosividade da chuva para $o$ Estado de Mato Grosso do Sul.

$\mathrm{Na}$ Tabela 4, são apresentados os indicadores estatísticos do ajuste entre os valores calculados de erosividade da chuva e os valores estimados pela RNA.

Tabela 4. Indicadores estatísticos do ajuste entre os valores calculados de erosividade da chuva e os valores estimados pela RNA.

\begin{tabular}{c|cc|c}
\hline \multicolumn{4}{c}{ Erosividade da chuva (MJ mm h $\left.\mathbf{~ h a ~}^{-\mathbf{1}} \mathbf{~} \mathbf{~}^{-\mathbf{1}}\right)$} \\
\hline $\mathbf{r}^{2}$ & $\mathbf{d}$ & $\mathbf{C}$ & Desempenho \\
\hline 0,95 & 0,98 & 0,95 & Ótimo \\
\hline
\end{tabular}

De acordo com os valores de $r^{2}$ e as classificações de desempenho, verifica-se a eficiência da RNA na estimativa da erosividade da chuva, apresentando desempenho classificado como "Ótimo" e índice de concordância (d) muito próximo de 1, situação que indica a concordância perfeita.

Do ponto de vista prático e com base nos resultados obtidos neste trabalho, a grande vantagem da utilização de RNAs na estimativa da erosividade local das chuvas está na utilização de dados de latitude, longitude e altitude de qualquer localidade, fato que possibilita estimar a erosividade das chuvas com a simples utilização, por exemplo, de um aparelho de GPS que forneça esses dados dos pontos de interesse. 


\section{CONCLUSÃO}

A utilização da Rede Neural Artificial (RNA) apresentada neste estudo mostra-se satisfatória na estimativa da erosividade local da chuva. Assim, podem-se obter os valores de erosividade de forma confiável para qualquer localidade do Estado de Mato Grosso do Sul, utilizando-se apenas dados de coordenadas geográficas e altitude.

A eficiência de RNAs para estimativa da erosividade da chuva é dependente das condições locais de cada região, da qualidade e da quantidade dos dados de entrada e da escolha e configuração de rede a ser utilizada.

\section{AGRADECIMENTOS}

Os autores expressam seus agradecimentos ao Conselho Nacional de Desenvolvimento Científico e Tecnológico - CNPq e à Fundação de Apoio ao Desenvolvimento do Ensino, Ciência e Tecnologia do Estado de Mato Grosso do Sul - Fundect, pela bolsa e pelo auxílio financeiro concedidos para a realização do trabalho. Os autores gostariam de agradecer, também, aos revisores anônimos pelos comentários e sugestões que contribuíram para melhoria deste trabalho.

\section{REFERÊNCIAS}

ANGULO-MARTÍNEZ, M.; BEGUERÍA, S. Estimating rainfall erosivity from daily precipitation records: a comparison among methods using data from the Ebro Basin (NE Spain). Journal of Hydrology, v. 379, n. 1/2, p. 111-121, 2009.

CAMARGO, A. P.; SENTELHAS, P. C. Avaliação do desempenho de diferentes métodos de estimativa da evapotranspiração potencial no estado de São Paulo, Brasil. Revista Brasileira de Agrometeorologia, v. 5, n. 1, p. 89-97, 1997.

CAPOLONGO, D.; DIODATO, N.; MANNAERTS, C. M.; PICCARRETA, M.; STROBL, R. O. Analyzing temporal changes in climate erosivity using a simplified rainfall erosivity model in Basilicata (southern Italy). Journal of Hydrology, v. 356, n. 1/2, p. 119- 130, 2008. http://dx.doi.org/10.1016/j.jhydrol.2008.04.002

IRVEM, A.; TOPALOGLU, F.; UYGUR, V. Estimating spatial distribution of soil loss over Seyhan River Basin in Turkey. Journal of Hydrology, v. 336, n. 1/2, p. 30-37, 2007. http://dx.doi.org/10.1016/j.jhydrol.2006.12.009

LICZNAR, P. Artificial neural networks use for rainfall-runoff erosivity factor estimation. Electronic Journal of Polish Agricultural Universities, v. 8, n. 1, 2005.

MARQUARDT, D. An algorithm for least squares estimation of non-linear parameters, Journal of the Society for Industrial and Applied Mathematics, v. 11, p. 431-441, 1963. http://dx.doi.org/10.1137/0111030

MANNAERTS, C. M.; GABRIEL, D. Rainfall erosivity in Cape Verde. Soil and Tillage Research, v. 55, n. 3/4, p.207-212, 2000. http://dx.doi.org/10.1016/S01671987(00)00104-5

MATHWORKS INC. Neural networks toolbox user's guide - version 6.0.1. Natick: MathWorks Inc., 2008. 
MELlO, C. R.; SÁ, M. A. C.; CURI, N.; MELlO, J. M.; VIOLA, M. R.; SILVA, A. M. Erosividade mensal e anual da chuva no Estado de Minas Gerais. R. Pesquisa Agropecuária Brasileira, v. 42, n. 4, p. 537-545, 2007.

MOREIRA, M. C.; PRUSKI, F. F.; OLIVEIRA, T. E. C.; PINTO, F. A. C.; SILVA, D. D. Redes neurais artificiais para estimativa mensal da erosividade da chuva no Estado de Minas Gerais. Revista Engenharia na Agricultura, v. 17, n. 1, p. 75-83, 2009.

MOREIRA, M. C.; PRUSKI, F. F.; OLIVEIRA, T. E. C.; PINTO, F. A. C.; SILVA, D. D. Neterosividade MG: erosividade da chuva em Minas Gerais. Revista Brasileira de Ciência do Solo, v. 32, p.1349-1353, 2008.

MOREIRA, M. C.; CECÍCILO, R. A.; PINTO, F. A. C.; PRUSKI, F. F. Desenvolvimento e análise de uma rede neural artificial para estimativa da erosividade da chuva para $\mathrm{o}$ Estado de São Paulo. Revista Brasileira de Ciência do Solo, v. 30, p. 1069-1076, 2006.

OLIVEIRA, P. T. S.; RODRIGUES, D. B. B.; ALVES SOBRINHO, T.; PANACHUKI, E. Estimativa do fator topográfico da USLE a partir de três algoritmos. Ambi-Agua, v. 5, n. 2, p. 217-225, 2010.

OLIVEIRA, P. T. S.; RODRIGUES, D. B. B.; ALVES SOBRINHO, T.; PANACHUKI, E. Processo analítico hierárquico aplicado à vulnerabilidade natural a erosão. Geociências, v. 28, n. 4, p. 417-424, 2009.

OLIVEIRA, P. T. S. Zoneamento ambiental no planejamento e gestão de bacias hidrográficas. 2011. 78f. Dissertação (Mestrado em Tecnologias Ambientais) Programa de Pós-graduação em Tecnologias Ambientais, Universidade Federal do Mato Grosso do Sul, Campo Grande, 2011.

ONYANDO, J. O.; KISOYAN, P.; CHEMELIL, M. C. Estimation of potential soil erosion for River Perkerra Catchment in Kenya. Water Resources Management, v.19, p.133143, 2005. http://dx.doi.org/10.1007/s11269-005-2706-5

RENARD, K. G.; FREIMUND, J. R. Using monthly precipitation data to estimate the Rfactor in the revised USLE. Journal of Hydrology, v. 157, n. 1/4, p. 287-306, 1994. http://dx.doi.org/10.1016/0022-1694(94)90110-4

RENSCHLER, C. S.; HARBOR, J. Soil erosion assessment tools from point to regional scales-the role of geomorphologists in land management research and implementation. Geomorphology, v. 47, n. 2/4, p.189-209, 2002. http://dx.doi.org/10.1016/S0169-555X(02)00082-X

SCHIETTECATTE, W.; D'HONDT, L.; CORNELIS, W. M.; ACOSTA, M. L.; LEAL, Z.; LAUWERS, N. et al. Influence of landuse on soil erosion riskin the Cuyaguateje watershed (Cuba). Catena, v. 74, n. 1, p. 1-12, 2008.

SHAMSHAD, A.; AZHARI, M. N.; ISA, M. H.; WAN HUSSIN, W. M. A.; PARIDA, B. P. Development of an appropriate procedure for estimation of RUSLE EI30 index and preparation of erosivity maps for Pulau Penang in Peninsular Malaysia. Catena, v. 72, n. 3, p. 423-432, 2008. http://dx.doi.org/10.1016/j.catena.2007.08.002 
AlVES SOBRINHO, T.; PERTUSSATTI, C. A.; REBUCCI, L. C. S.; OLIVEIRA, P. T. S. Estimativa da erosividade local das chuvas, utilizando redes neurais artificiais. Ambi-Agua, Taubaté, v. 6, n. 2, p.246-254, 2011. (doi:10.4136/ambi-agua.197)

SILVA, A. M. Rainfall erosivity map for Brazil. Catena, v. 57, n. 3, p. 251-259, 2004. http://dx.doi.org/10.1016/j.catena.2003.11.006

SILVA, R. B.; IORI, P.; ARMESTO, C.; BENDINI, H. N. Assessing rainfall erosivity with artificial neural networks for the Ribeira Valley, Brazil. International Journal of Agronomy, 2010. 7p. http: //dx.doi.org/10.1155/2010/365249

WILlMOTT, C. J.; DAVIS, R. E.; FEDDEMA, J. J.; JOHANNES, J.; KLINK, K. M.; LEGATES, D. R. et al. Statistics for the evaluation and comparison of models. Journal of Geophysical Research Atmospheres, v. 90, n. C5, p. 8995-9005, 1985. http://dx.doi.org/10.1029/JC090iC05p08995

WISCHMEIER, W. H.; SMITH, D. D. Predicting rainfall erosion losses: a guide to conservation planning. Washington: USDA, 1978. 58p. (Agriculture Handbook, 537) 